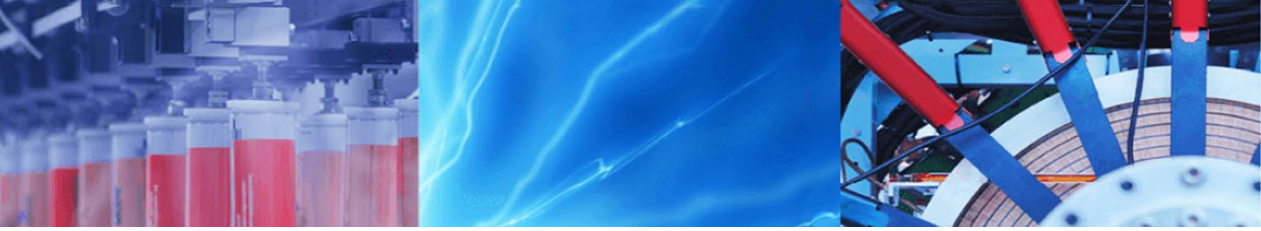

Research Article

\title{
Prediction of residual stress using RSM during turning of Ti-6AI-4V with the 3D FEM assist and experiments
}

\author{
Neelesh Kumar Sahu' · Atul B. Andhare ${ }^{2}$
}

(c) Springer Nature Switzerland AG 2019

\begin{abstract}
Machining of titanium alloy is known to be complex due to problems like low thermal conductivity, high thermal and residual stresses, chemical reactions, phase transformation during process, etc. These complexities affect the quality of surface produced and hence the performance of machined components. In the evaluation of surface integrity of machined components, residual stresses are the most critical response as it affects fatigue life of component. Present work aimed at developing prediction model for the residual stress induced due to machining of Ti-6Al-4V. 3D finite element simulations are performed to determine residual stress in turning of Ti-6Al-4V using carbide inserts. Simulations are performed in sequential manner using design of experiments through response surface methodology and an empirical model is developed. Later on actual machining is performed for few of the experimental runs and residual stresses are measured through X-ray diffraction method and the simulation results are compared with experimental results. These results are found in good agreement with average absolute error of $11 \%$. The influence of the feed rate, cutting speed and depth of cut variations on the induced residual stress is investigated and analysed using analysis of variance. Results show that magnitude of surface compressive residual stress increases with cutting speed and depth of cut whereas it reduces with feed rate. Additionally, optimization was done with response surface desirability approach for optimum cutting parameters to maximize surface compressive residual stress. Optimum cutting parameters were found as cutting speed $171.4 \mathrm{~m} / \mathrm{min}$ (1704.5 RPM), feed rate $0.07 \mathrm{~mm} / \mathrm{rev}$ and $0.8 \mathrm{~mm}$ depth of cut (doc) with corresponding residual stress as $-1495.97 \mathrm{MPa}$.
\end{abstract}

Keywords Residual stress $\cdot$ RSM $\cdot 3$ D simulation $\cdot$ X-ray diffraction $\cdot$ Optimization

\section{Introduction}

Titanium alloys are utilised in biomedical and aviation industries. Main reasons for use in these industries are their superior properties like high strength, low density and high temperature and corrosion resistance. On the other hand titanium alloys poses difficulty in machining due to low thermal conductivity, chemical reaction with tool, variation of chip thickness and residual stress $[1,2]$. Tables 1 and 2 shows the mechanical properties and chemical composition of Ti-6Al-4V. Machining is an important process for many components in their manufacturing cycle. During such processes, engineering components are subjected to high stresses and strains of variable magnitudes and nature. Even after machining some of these stresses remain on the surface of machined parts and are called as residual stresses. These stresses are critical because of their significant effect on the fatigue life of machined components $[3,4]$. These stresses occur mainly due to work hardening in the sub-surface of the workpiece material and thermal softening at the surface due to cutting conditions [3]. During machining of titanium

\footnotetext{
$\triangle$ Neelesh Kumar Sahu, neeleshmecher@gmail.com; Atul B. Andhare, abandhare@mec.vnit.ac.in | ${ }^{1}$ Department of Mechanical Engineering, Medi-Caps University, Indore 453331, India. ${ }^{2}$ Department of Mechanical Engineering, Visvesvaraya National Institute of Technology, Nagpur 440010, India.
}

SN Applied Sciences (2019) 1:891 | https://doi.org/10.1007/s42452-019-0809-5 
Table 1 Physical properties of Ti-6Al-4V

\begin{tabular}{lllllll}
\hline Density $\left(\mathrm{g} / \mathrm{cm}^{3}\right)$ & $\begin{array}{l}\text { Melting range } \\
\left({ }^{\circ} \mathrm{C} \pm 15^{\circ} \mathrm{C}\right)\end{array}$ & $\begin{array}{l}\text { Specific heat }(\mathrm{J} / \\
\left.\mathrm{kg}{ }^{\circ} \mathrm{C}\right)\end{array}$ & $\begin{array}{l}\text { Thermal conduc- } \\
\text { tivity }(\mathrm{W} / \mathrm{m} \mathrm{K})\end{array}$ & $\begin{array}{l}\text { Elastic modulus } \\
(\mathrm{GPa})\end{array}$ & $\begin{array}{l}\text { Hardness rockwell } \\
(\mathrm{HRC})\end{array}$ & $\begin{array}{l}\text { Tensile strength } \\
(\mathrm{MPa})\end{array}$ \\
\hline 4.42 & 1649 & 560 & 7.2 & 114 & 36 & 897 \\
\hline
\end{tabular}

Table 2 Chemical composition of $\mathrm{Ti}-6 \mathrm{Al}-4 \mathrm{~V}$

\begin{tabular}{ll}
\hline Composition & $\%$ \\
\hline Aluminium (Al) & 6.75 \\
Vanadium (V) & 4.5 \\
Carbon (C) & 0.08 \\
Iron (Fe) & 0.25 \\
Oxygen (O) & 0.20 \\
Nitrogen (N) & 0.05 \\
Hydrogen (H) & 0.015 \\
Titanium (Ti) & Balance \\
\hline
\end{tabular}

alloys high heat remains at cutting zone and influence the machined surface and subsurface [5]. Titanium alloys are used in floor beam fittings in aircraft as well as knee hip joints in biomedical industries. Therefore, these components require high reliability and fatigue life. Tensile Stresses generated in the machined surface propagate crack initiation and are unfavourable to fatigue life of the component. Therefore, sometimes alternate costly surface treatments are performed to create desirable compressive stress over machined surface [5-7]. Therefore, prediction of residual stresses while machining of titanium alloys is important and being attempted for some time now. From the literature it is noted that residual stresses are greatly influenced by cutting parameters and tool geometry [8-12]. It was found that generally at higher feed rate along with lower cutting speed, tensile residual stress increases at machined surface. On the other hand Mohammadpour et al. [12] found that the maximum tensile residual stresses increased with increasing the cutting speed and feed rate in orthogonal cutting of AISI 1045. Larger negative rake angle, large edge radii and coating applied over tool tends to produce compressive stresses at surface and increase depth of effective zone $[4,6,13]$. There are number of reports on experiments performed for measuring residual stresses and different arguments are found regarding effect of cutting parameters and tool parameters on residual stress. These differences in results are due to different work piece and tool materials and cutting conditions used. However, conducting such experiments is expensive and time consuming for machining of titanium alloys. Therefore, researchers are focusing on finite element method (FEM) based simulation technique for predicting residual stress in machining. Few studies are found in literature, which mainly focus on using FEM in predicting residual stresses. In most of the literature Johnson-Cook model is used for work material behaviour and Lagrangian and Eulerian models are used for computing and meshing $[4,6,14-17]$. Ozel and Zeren [14] and Prasad [18] performed finite element modelling to predict stresses with arbitrary Lagrangian and Eulerian model and found better results. Salio et al. [19] performed simulated turning in turbine disks, using nonlinear finite element code MSC. Marc. Their results gave knowledge about selection of cutting parameters and the predicted and experimental residual stresses were found to be in acceptable limit. From the above works, information on residual stress formation and use of finite element method was gained. However, use of finite element method in prediction of residual stress during machining of Ti6Al4V is not reported much and there is a scope to advance the reported predictive methods and optimize the simulation process. The main objective of the present work is to find out effectiveness of each cutting parameter over machine induced residual stress. An effort was made to develop empirical predictive model to predict residual stress based on the cutting parameters. Later on, optimization is done based on response surface optimizer to find out the optimum cutting parameters for getting maximum compressive hoop stress. Following sections present the work in detail.

\section{Materials and methods}

This section describes the actual machining and 3D simulation conditions used for turning of Ti-6Al-4V. Details of residual stress measured experimentally are also included below.

\subsection{Work material, cutting tools and cutting parameters}

Workpiece material was selected as Ti-6Al-4V grade 5 (32 mm diameter and $100 \mathrm{~mm}$ length) for turning operation. CVD $\left(\mathrm{TiCN}+\mathrm{Al}_{2} \mathrm{O}_{3}+\mathrm{TiN}\right)$ coated tungsten carbide inserts with $7^{\circ}$ rake angle, $0^{\circ}$ clearance angle, $5 \mathrm{~mm}$ thickness, $16 \mathrm{~mm}$ edge length and $0.794 \mathrm{~mm}$ nose radius were used as cutting tools material. Table 3 shows the thermo physical properties of tool and workpiece material. Machine tool specifications for turning operations are: 
Table 3 Thermo-physical properties of work and tool material

\begin{tabular}{lll}
\hline Property & WC tool & Ti-6Al-4V \\
\hline Density $\left(\mathrm{kg} / \mathrm{m}^{3}\right)$ & 15,000 & 4430 \\
Poisson's ratio & 0.2 & 0.342 \\
Young's modulus $(\mathrm{GPa})$ & 800 & 113.8 \\
Thermal conductivity $(\mathrm{W} / \mathrm{m}-\mathrm{K})$ & 110 & 7.1 \\
Specific heat $(\mathrm{J} / \mathrm{kg} / \mathrm{K})$ & 203 & 530 \\
Thermal expansion $\left(\mu \mathrm{m} / \mathrm{m}-{ }^{\circ} \mathrm{C}\right)$ & 5.5 & 8.6 \\
\hline
\end{tabular}

MTAB CNC lathe machine (Maxturn ++); power capacity of $5.5 \mathrm{~kW}$; Controller Sinumeric 828D; precise motion and spindle speed control with $\pm 0.005 \mathrm{~mm}$ position accuracy and repeatability $\pm 0.004 \mathrm{~mm}$. Cutting forces were measured with Kistler 9257BA dynamometer interfaced with control unit 5233A1. The dynamometer was mounted on turret with fixture as shown in Fig. 1. Dynamometer reading was seen and recorded in LabVIEW 2012 with NI DAQ 9178 interface. Machining was performed under dry conditions (without cutting fluid). Residual stress was analysed after machining by $\mathrm{X}$-ray diffraction technique using uniaxial $\sin ^{2} \psi$ method. Where, sample is tilted at different $\Psi$ angle which is formed due to intersection of the line normal to the sample and the line normal to the diffracting plane (dividing equally the incident and diffracted beams).

Cutting parameters used as variables are cutting speed, feed rate and depth of cut. List of experiments are generated systematically using central composite design (CCD) under RSM. The distributions of variables in terms of levels under CCD are mainly as factorial points (the corners of a cube), center and axial (or star) points. This arrangement helps to determine second order effects over the response. The five levels of design variables are possible due to addition of axial points. The axial point distance from the

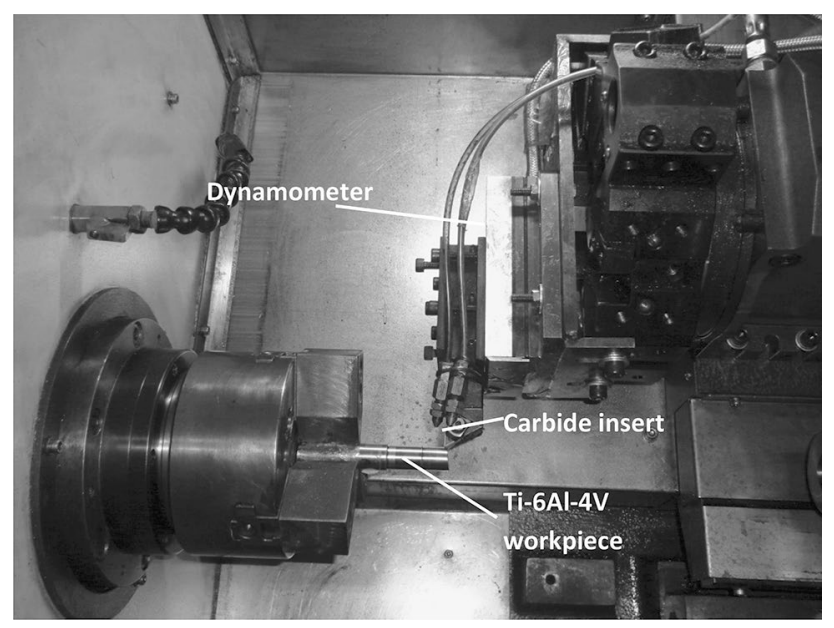

Fig. 1 Machining set up with dynamometer center are calculated using formula $a=2^{k / 4}$, where $k$ is number of design variables. In the present work, levels of cutting parameters used are shown in Table 4. Design of experiment was performed using MINITAB 16 software and experiments are performed in standard order.

\subsection{Simulation details}

In this study, the Finite Element Method software DEFORM $^{3 \mathrm{D}}$ version 10.0, which employs an updated Lagrangian formulation that involves remashing based on implicit integration method for large deformation at cutting zone is used to simulate the three dimensional turning operation of Ti- $6 \mathrm{Al}-4 \mathrm{~V}$. Turning operation is modelled with defined geometry and properties of workpiece and tool are as shown in Fig. 2a. The analysis uses the updated Lagrangian model (Arbitrary Lagrangian-Eulerian model ALE) formulation with the automatic remeshing method. ALE formulation efficiently performed for simulating highly non-linear problems such as machining which involve large deformation and change in contact positions $[14,19,20]$. When the software detects element distortion, a new mesh is generated as shown in Fig. 2b. Use of adapting meshing allows the chip formation and plastic flow of work material therefore chip separation criterion is not required in the proposed FEM model. In the present work, tool chip interface friction is determined using following models: (1) a shear friction region $(n=\hat{J} / k)$ here $\hat{J}$ is shear stress and $k$ is shear flow stress near tool round edge $(n=0.9) 2$. In sliding region along rake face, frictional shearing stress can be determined using coefficient of friction and normal stress.

The finite element mesh of the work piece is modelled using around 25,000 tetrahedral elements. The work piece geometry is generated by the machining wizard, using the 3D simplified turning operation model. The mesh is equally distributed throughout the work piece. The tool is selected as a master object and the work piece is defined as the slave object. Chen et al. [21] performed turning operation on Ti-6Al-4V under varying cutting parameters (cutting speed $75-200 \mathrm{~m} / \mathrm{min}$; chip thickness $0.127-0.2 \mathrm{~mm}$ and width of cut $0.76-3.2 \mathrm{~mm}$ ) for friction modelling based on Coulomb's friction law. After performing regression analysis between coefficient of friction and cutting parameters, the coefficient of friction for flank face/workpiece interface was

Table 4 Cutting parameters and their level for machining

\begin{tabular}{lclllc}
\hline Level-> & Lowest & Low & Center & High & Highest \\
\hline Coded value $(\mathrm{x})$ & -1.682 & -1 & 0 & 1 & 1.682 \\
Cutting Speed $\mathrm{V}_{\mathrm{c}}(\mathrm{m} / \mathrm{min})$ & 69.9 & 90.4 & 120 & 150 & 171.4 \\
Feed rate $\mathrm{f}(\mathrm{mm} / \mathrm{rev})$ & 0.07 & 0.1 & 0.15 & 0.2 & 0.23 \\
Depth of cut $(\mathrm{mm}) \mathrm{a}_{\mathrm{p}}$ & 0.33 & 0.5 & 0.75 & 1 & 1.17 \\
\hline
\end{tabular}




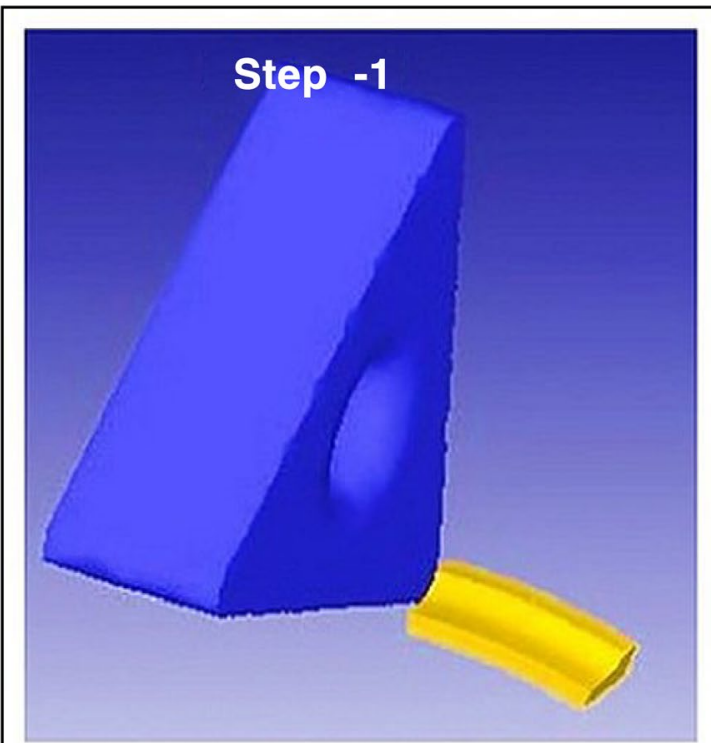

(a) Tool movement in simulation in 3D
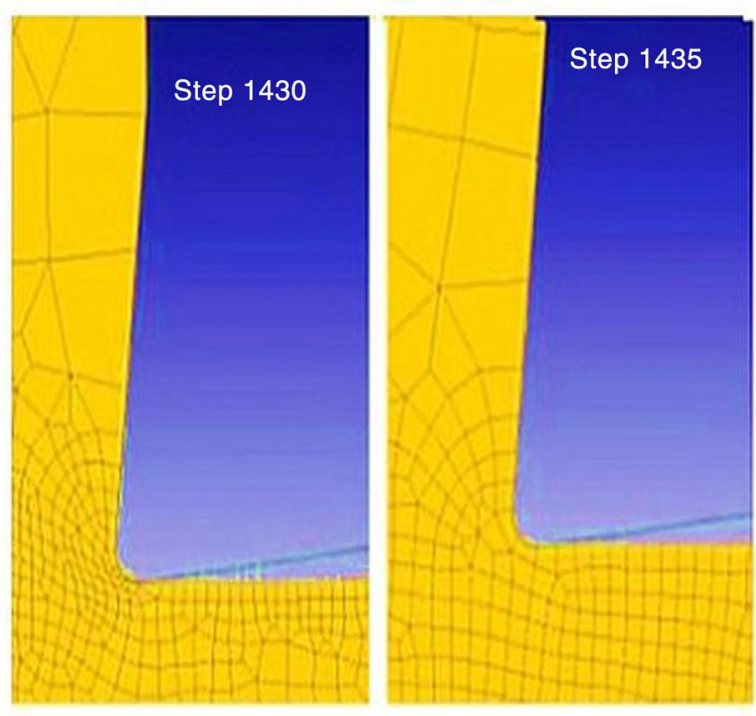

(b) Remeshing procedure at cutting zone

Fig. 2 Simulation of turning operation

suggested as 0.3 by Chen et al. [21]. Therefore in the present work based on same work material and cutting parameters, Coulomb model of friction with a friction coefficient of 0.3 is used to simulate the friction between the tool and the work piece. Segmental chips were formed due to this friction model which is also observed in turning operation confirms the findings of Chen el al. [21]. 70\% of heat is transferred to tool insert because of low thermal conductivity of titanium alloys. The constant heat transfer coefficient $h=100 \mathrm{~kW} /$ $\mathrm{m}^{2} \mathrm{~K}$ is used for simulation to allow rapid temperature rise in the tool. At high cutting speed, there is negligible transfer of heat through conduction therefore very high temperature in chip occurs due to adiabatic conditions.

The modelling of the flow stress in the work piece material is one of the most important aspects in considering the simulation of a metal cutting process. Flow stress is the instantaneous value of yield stress and is represented mathematically by constitutive equations depending on strain, strain-rate and temperature. Johnson-Cook [19, 22] is a constitutive material model which accommodates to large strains, high strain rates and high temperatures is shown in Eq. 1.

$\sigma_{\text {eq }}=\left(A+B \varepsilon^{n}\right)\left(1+C \ln \left(\frac{\dot{\varepsilon}}{\dot{\varepsilon}_{0}}\right)\right)\left(1-\left(\frac{T-T_{\text {room }}}{T_{m}-T_{\text {room }}}\right)^{\mathrm{m}}\right)\left(\frac{\dot{\varepsilon}}{\dot{\varepsilon}_{0}}\right)^{\alpha}$

where $\varepsilon$ is the plastic strain, $\dot{\varepsilon}$ is the strain rate $\left(\mathrm{s}^{-1}\right), \dot{\varepsilon}_{0}$ is the reference plastic strain rate $\left(\mathrm{s}^{-1}\right), \mathrm{T}\left({ }^{\circ} \mathrm{C}\right)$ is the workpiece temperature, $T_{m}\left(1660^{\circ} \mathrm{C}\right)$ is the melting temperature of the work piece material $(\mathrm{Ti}-6 \mathrm{Al}-4 \mathrm{~V})$ and $\mathrm{T}_{\text {room }}\left(20^{\circ} \mathrm{C}\right)$ is the room temperature. Coefficient $\mathrm{A}(\mathrm{MPa})$ is the yield strength, $B(\mathrm{MPa})$ is the hardening modulus, $C$ is the strain rate sensitivity coefficient, $\mathrm{n}$ is the hardening coefficient and $\mathrm{m}$ the thermal softening coefficient. Residual stress in a machined surface is induced due to strained crystal structure in the crystalline materials because of mechanical deformation, phase transformation and thermal expansion. Mechanisms involved in variations in residual stress are combination of mechanical, thermal and chemical deformations between the tool and workpiece $[4,5,10$, 23]. It is reported in the literature that thermal load results in tensile residual stress and mechanical load causes compressive residual stresses [7, 10, 24-26]. During cutting, high temperature is generated which causes thermal expansion and plastic flow over the workpiece surface. During the subsequent cooling of machined surface, thermal contraction is higher than plastic deformation produce due to mechanical loading [27]. This phenomenon originates tensile residual stresses in machining.

Material behaviour for under dynamic conditions is broadly found in literatures [14, 27-29]. Conditions used to found stress, strain rate, are similar to use for present work. Nemat-Nasser et al. [29] observed strain (flow) softening due to adiabatic shearing of Ti-Al-4V. This results in less resistance to deformation due to rearrangement of dislocations because of cycling of hard materials. Lee and Lin [30] showed flow stress data for temperature ranges from 20 to $1100{ }^{\circ} \mathrm{C}$ and strain rate started from 800 to $3300 \mathrm{~s}^{-1}$ using Johnson-Cook Model. From the literature based on simulation using Johnson-Cook model over Ti-6Al-4V Johnson-cook material model constant values for Ti-6AI-4V are shown in Table 5. The chosen parameters 
Table 5 Johnson-Cook constitutive material model constants [30]

\begin{tabular}{llllllll}
\hline Material & $\mathrm{A}(\mathrm{MPa})$ & $\mathrm{B}(\mathrm{MPa})$ & $\mathrm{C}$ & $\mathrm{n}$ & $\mathrm{m}$ & $\varepsilon_{0}$ & $\mathrm{a}$ \\
\hline Ti-6Al-4V & 862.5 & 683.1 & 0.012 & 0.35 & 1 & 1 & 0 \\
\hline
\end{tabular}
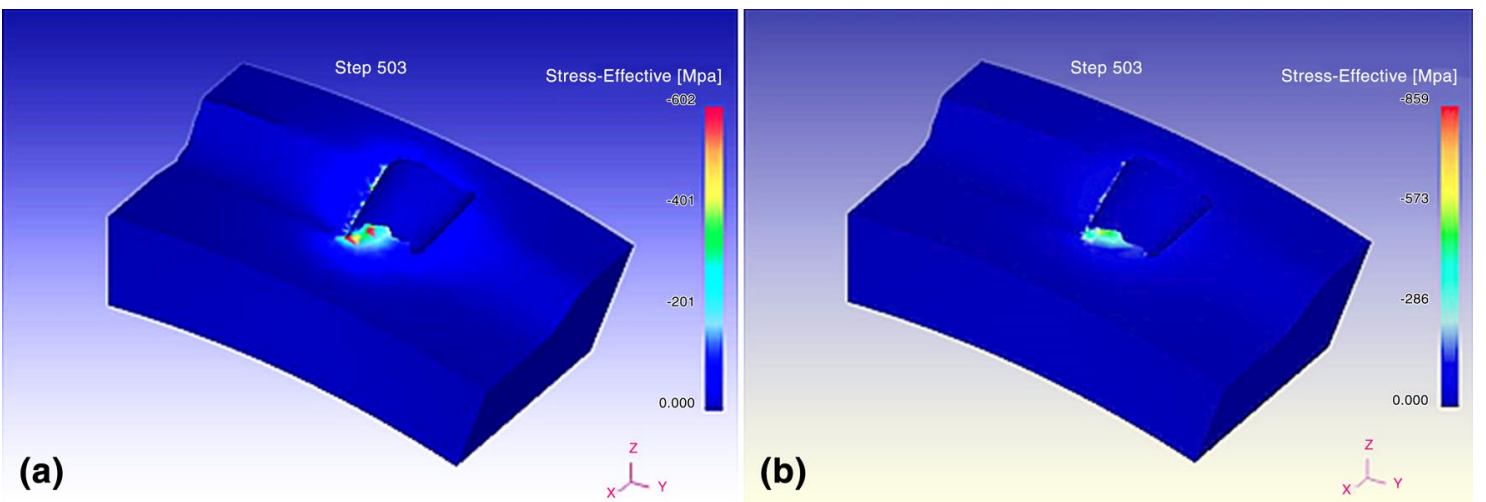

Fig. 3 Residual stress simulation a cutting speed: $150.8 \mathrm{~mm} / \mathrm{min}$, feed rate: $0.1 \mathrm{~mm} / \mathrm{rev}$, depth of cut: $0.5 \mathrm{~mm}$ and b cutting speed: $90.4 \mathrm{~mm} /$ $\mathrm{min}$, feed rate: $0.1 \mathrm{~mm} / \mathrm{rev}$, depth of cut: $0.5 \mathrm{~mm}$

are validated with experimentally measured cutting forces and residual stresses.

The data collection was performed at one point for every set of parameters. By the definition of residual stress; it is the stress remaining in the machined component after all the external loads are removed; the component being relaxed. Therefore, when the data for residual stress were collected, data points were taken considering time to remove the cutting tool out of the work piece to relax the component in means of strains and stresses respectively. Figure $3 a$, $b$ shows the hoop (circumferential) residual stress simulated on the workpiece after being relaxed.

\subsection{Experimental residual stress}

X-ray diffraction technique was used for residual stress calculations. Residual stresses were evaluated by XPert MRD (XL) software using uniaxial $\sin ^{2} \Psi$ method. Residual stresses are measured through measuring strains by calculating change in interplaner spacing between strain free crystals and strained crystals in the crystal lattice as shown in Eq. 2. Whereas, strain free interplaner spacing is calculated by measuring the angles at which the maximum diffracted intensity (intensity $V_{s} 2 \theta$ graph) take place when a crystalline sample is subjected to $X$-rays. From these angles it is possible to obtain the interplaner spacing of the diffraction planes using Bragg's law [19].

$$
\sigma=\frac{E}{(1+v) \sin ^{2} \psi}\left(\frac{d_{\psi}-d_{n}}{d_{n}}\right)
$$

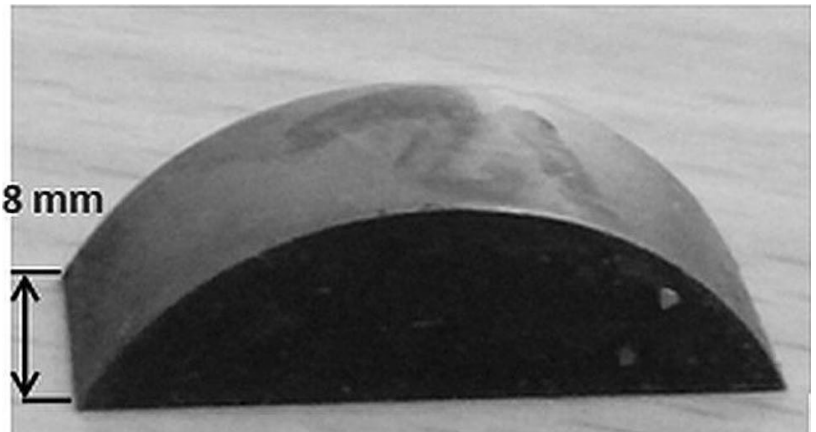

Fig. 4 Sample cut through wire cut EDM

where $d_{n}=$ Space between planes containing atoms normal to the surface in $A^{\circ} ; d_{\psi}=$ spacing between atomic planes at an angle $\psi$ to the surface in $A^{\circ} ; E=$ Young's modulus; $v=$ Poison's ratio; $\Psi=$ angle formed due to intersection of the normal of the sample and the normal of the diffracting plane in degrees.

The above equation permits to estimate the stress for arbitrary direction from the inter-planar spacing observed from two measurements, made in a plane normal to the surface and containing the direction of the stress to be measured. Samples of $8 \mathrm{~mm}$ thickness as shown in Fig. 4 were cut by wire cut EDM after performing turning operation on Ti-6Al-4V. These samples were taken for residual stress measurement using $\mathrm{X}$-ray diffraction technique. Experimentation was performed using cutting parameters same as used in simulations for comparison purpose. Radiation of X Rays were taken as Cu Ka with $1.5406 \mathrm{~A}^{\circ}$ 


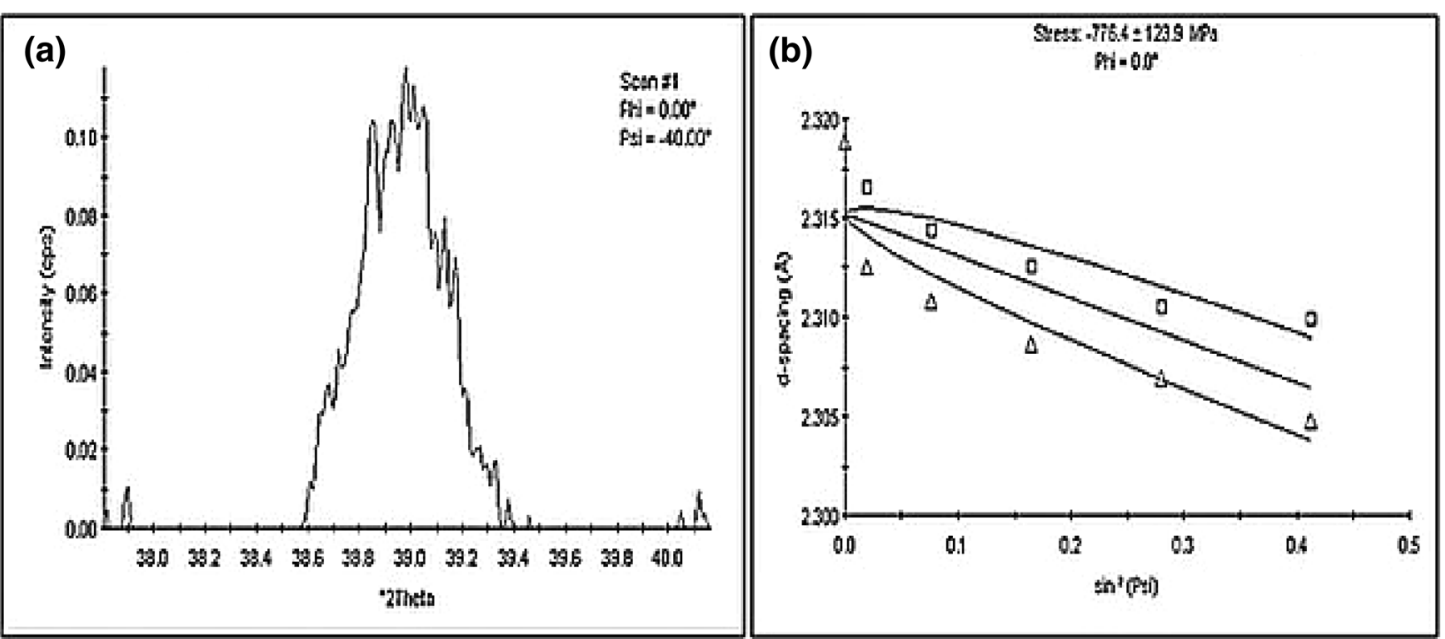

Fig. 5 a Intensity $V_{s} 2 \theta$ and $\mathbf{b} d$ spacing $V_{s} \sin ^{2} \psi$ for cutting speed $=90.4 \mathrm{~m} / \mathrm{min}$, feed rate $=0.1 \mathrm{~mm} / \mathrm{rev}$ and depth of cut $=0.5 \mathrm{~mm}$

wavelength. Bragg angle $2 \theta$ was taken as $139.4^{\circ}$ for rotation of the sample.

The atom spacing in crystal lattice, measured by resolving angular peak shift from 2-theta versus intensity plot of X-rays as a curve similar to that shown in Fig. 5 a. This angular peak shift is then applied to Bragg's law to calculate $d$ spacing. Residual stress determines experimentally using $\sin ^{2} \psi$ method. XRD measurements are made at different tilts in the $\sin ^{2} \psi$ method. "d-spacing versus $\sin ^{2} \psi^{\prime \prime}$ graph for all $\psi$ tilts of sample were plotted for the samples as shown in Fig. 5 b. The residual stress on the plane of surface is proportional to $X$-ray elastic constant $(E /(1+v))$ multiplied by slope obtained from Fig. $5 b$ [20]. From Fig. $5 b$, it is clear that linear plot $d$-spacing versus $\sin ^{2}$ $\Psi$ plot corresponds to homogeneous strain distribution over X-ray irradiated volume indicates that the strain distribution is homogeneous within the X-ray irradiated volume. This suggests the condition of plane stress. Cutting parameters used for the above sample graph were cutting speed $=90.4 \mathrm{~mm} / \mathrm{min}$, feed rate $=0.1 \mathrm{~mm} / \mathrm{rev}$, depth of cut $=0.5 \mathrm{~mm}$. similar graphs were plotted and residual stress calculations were done for other five samples. The stress can be obtained by calculating the slope of the line from $d$-spacing versus $\sin ^{2} \psi$ and along with information of the elastic properties of the material.

\subsection{Response surface methodology}

In the present work, response surface methodology (RSM) is used to study the effect of each cutting parameter on residual stress induced in the machined component. Later on, predicted model is also developed to estimate residual stress based on cutting parameters. RSM is a method used to create functional liaison between the measured output (residual stress) of any process and allied control (cutting parameters) variables [29-31]. In order to avoid costly experiments, simulations were performed based on design of experiments and ranges of cutting parameters are used form Table 2. Second order quadratic model is generated based on response surface methodology as shown in Eq. 3.

$\mathrm{R}=\mathrm{c}_{0}+\sum_{i=1}^{n} \mathrm{c}_{\mathrm{i}} \mathrm{y}_{\mathrm{i}}+\sum_{\mathrm{i}=1}^{\mathrm{n}} \mathrm{c}_{\mathrm{ii}} \mathrm{y}_{\mathrm{i}}^{2}+\sum_{\mathrm{i}=1}^{\mathrm{n}-1} \sum_{\mathrm{j}=\mathrm{i}+1}^{\mathrm{n}} \mathrm{c}_{\mathrm{ij}} \mathrm{y}_{\mathrm{i}} \mathrm{y}_{\mathrm{j}}+\varepsilon$

where $\mathrm{R}$ is response to be predicted; $\mathrm{c}_{0}, \mathrm{c}_{\mathrm{i}}$ are regression coefficients $y_{i}$ are design variables and $\varepsilon$ is error involve in data. Regression coefficients are calculated by least square method in Eq. 3.

\section{Results and discussions}

This section shows the results obtained from simulations and its comparison with experimental results. In this study, Analysis of variance (ANOVA) and estimation of regression coefficients were performed with MINITAB 16 software. Main effect plots were obtained with the help of regression analysis. Simulations on all set of data were performed according to design of experiment and resultant residual stresses are shown in Table 6. Similarly, Table 5 shows the results obtained from experimentally measured residual stress using X-ray diffraction after turning operation for six samples.

From Tables 6 and 7 it is clear that residual stress in machined surfaces of titanium alloys for experiments and simulations under explored ranges of cutting 
Table 6 Design of experiment and corresponding residual stress

\begin{tabular}{lclll}
\hline Std order & $\begin{array}{l}\text { Cutting speed } \mathrm{V}_{\mathrm{c}} \\
(\mathrm{m} / \mathrm{min})\end{array}$ & Feed $(\mathrm{mm} / \mathrm{rev})$ & $\begin{array}{l}\text { Depth of cut } \\
(\mathrm{mm}) \mathrm{a}_{\mathrm{p}}\end{array}$ & $\begin{array}{l}\text { Hoop (circumferential) } \\
\text { residual stress RS (MPa) }\end{array}$ \\
\hline 1 & 90.4 & 0.1 & 0.5 & -700.81 \\
2 & 150.8 & 0.1 & 0.5 & -850.83 \\
3 & 90.4 & 0.2 & 0.5 & -601.3 \\
4 & 150.8 & 0.2 & 0.5 & -858.47 \\
5 & 90.4 & 0.1 & 1 & -913.7 \\
6 & 150.8 & 0.1 & 1 & -1419.18 \\
7 & 90.4 & 0.2 & 1 & -410.34 \\
8 & 150.8 & 0.2 & 1 & -1086.2 \\
9 & 69.9 & 0.15 & 0.75 & -350.52 \\
10 & 171.4 & 0.15 & 0.75 & -950.43 \\
11 & 120.6 & 0.07 & 0.75 & -783.91 \\
12 & 120.6 & 0.23 & 0.75 & -206.1 \\
13 & 120.6 & 0.15 & 0.33 & -318.98 \\
14 & 120.6 & 0.15 & 1.17 & -982.1 \\
15 & 120.6 & 0.15 & 0.75 & -425.65 \\
16 & 120.6 & 0.15 & 0.75 & -425.65 \\
17 & 120.6 & 0.15 & 0.75 & -425.65 \\
18 & 120.6 & 0.15 & 0.75 & -425.65 \\
19 & 120.6 & 0.15 & 0.75 & -425.65 \\
20 & 120.6 & 0.15 & 0.75 & -425.65 \\
\hline & & & &
\end{tabular}

\begin{tabular}{lcllc}
\hline Std order & $\begin{array}{l}\text { Cutting speed }(\mathrm{m} / \\
\mathrm{min})\end{array}$ & Feed $(\mathrm{mm} / \mathrm{rev})$ & $\begin{array}{l}\text { Depth of cut } \\
(\mathrm{mm})\end{array}$ & $\begin{array}{l}\text { Hoop (circumferential) } \\
\text { residual stress }(\mathrm{MPa})\end{array}$ \\
\hline 1 & 90.4 & 0.1 & 0.5 & $-776.4 \pm 123.9$ \\
4 & 150.8 & 0.2 & 0.5 & $-1000.7 \pm 156.0$ \\
9 & 69.9 & 0.15 & 0.75 & $-338.0 \pm 87.7$ \\
10 & 171.4 & 0.15 & 0.75 & $-813.6 \pm 130.0$ \\
12 & 120.6 & 0.23 & 0.75 & $-173.4 \pm 133.9$ \\
15 & 120.6 & 0.15 & 0.75 & $-394.6 \pm 174.1$ \\
\hline
\end{tabular}

Table 7 Residual stress measured after experiments physical properties such as thermal conductivity, hardness and microstructure of titanium alloys $[7,40]$. Other reasons for different results are dissimilar cutting conditions as well as differences in tool geometry Ulutan et al. [3].

Figure 6 shows the comparison between experimental and simulation values of residual stress. The error ranges from $3.5 \%$ for cutting speed $=69.9 \mathrm{~m} / \mathrm{min}$; feed rate $=0.15 \mathrm{~mm} / \mathrm{rev}$; depth of cut $=0.5 \mathrm{~mm}$ to $18.75 \%$ for cutting speed $=120.6 \mathrm{~m} / \mathrm{min}$; feed rate $=0.15 \mathrm{~mm} /$ rev; depth of cut $=0.5 \mathrm{~mm}$. Majority of experimental values are close to simulation results and thus validate the simulation results. The variations in these two values occur due to slight variations in actual machining and measuring conditions and also due to different atmospheric temperature while performing actual machining. In addition to residual stress, cutting forces were also measured experimentally in three 


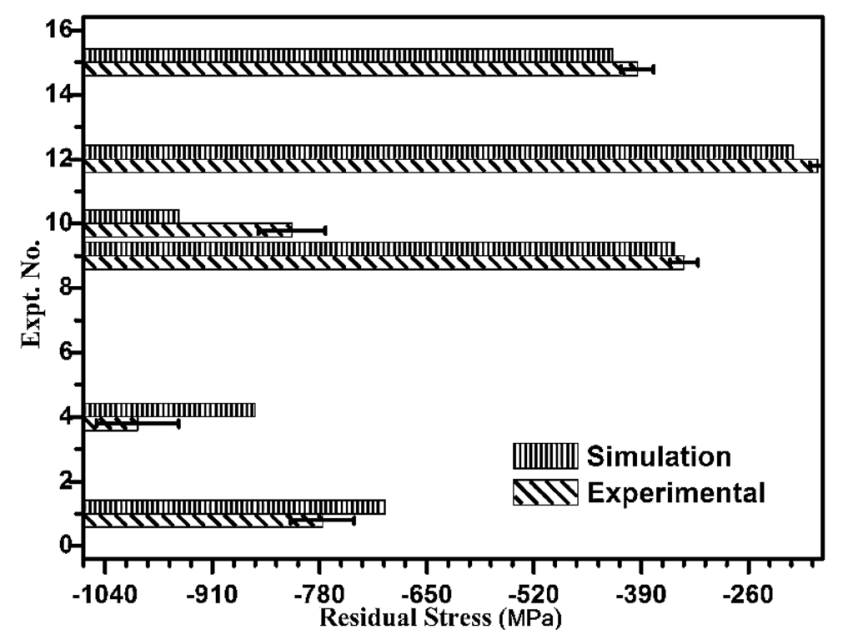

Fig. 6 Comparison between experimental and simulation residual stress

directions and resultant of these forces was taken and compared with simulated results. Figure 7 shows the comparison between experimentally measured and simulated cutting forces and the error ranges from $9 \%$ at cutting speed $=171.4 \mathrm{~m} / \mathrm{min}$, Feed rate $=0.15 \mathrm{~mm} /$ rev and depth of cut $=0.75 \mathrm{~mm}$ to $20 \%$ at cutting speed $=120.6 \mathrm{~m} / \mathrm{min}$, Feed rate $=0.23 \mathrm{~mm} / \mathrm{rev}$ and depth of cut $=0.75 \mathrm{~mm}$. Possible reason for these
Table 8 ANOVA for residual stress model

\begin{tabular}{llrlrl}
\hline Source & Sum of square & DF & Mean of square & $\mathrm{F}$ value & $\begin{array}{l}\text { P value } \\
\text { Prob }>\mathrm{F}\end{array}$ \\
\hline Model & $1.679 \mathrm{E}+006$ & 9 & $1.866 \mathrm{E}+005$ & 7.93 & 0.0016 \\
$\mathrm{~V}_{\mathrm{c}}$ & $4.940 \mathrm{E}+005$ & 1 & $4.940 \mathrm{E}+005$ & 21.01 & 0.0010 \\
$\mathrm{~F}$ & $2.643 \mathrm{E}+005$ & 1 & $2.643 \mathrm{E}+005$ & 11.24 & 0.0073 \\
$\mathrm{a}_{\mathrm{p}}$ & $2.737 \mathrm{E}+005$ & 1 & $2.737 \mathrm{E}+005$ & 11.64 & 0.0066 \\
$\mathrm{~V}_{\mathrm{c}} \times \mathrm{f}$ & 9627.86 & 1 & 9627.86 & 0.41 & 0.5367 \\
$\mathrm{~V}_{\mathrm{c}} \times \mathrm{a}_{\mathrm{p}}$ & $74,913.53$ & 1 & $74,913.53$ & 3.19 & 0.1046 \\
$\mathrm{a}_{\mathrm{p}} \times \mathrm{f}$ & $69,279.45$ & 1 & $69,279.45$ & 2.95 & 0.1168 \\
$\mathrm{~V}_{\mathrm{c}} 2$ & $2.488 \mathrm{E}+005$ & 1 & $2.488 \mathrm{E}+005$ & 10.58 & 0.0087 \\
$\mathrm{f}^{2}$ & $84,159.65$ & 1 & $84,159.65$ & 3.58 & 0.0878 \\
$\mathrm{a}_{\mathrm{p}} 2$ & $2.489 \mathrm{E}+005$ & 1 & $2.489 \mathrm{E}+005$ & 10.58 & 0.0087 \\
Residual & $2.352 \mathrm{E}+005$ & 10 & $23,516.55$ & & \\
Lack of fit & $2.352 \mathrm{E}+005$ & 5 & $47,033.09$ & & \\
Pure error & 0.000 & 5 & 0.000 & & \\
Core total & $1.914 \mathrm{E}+006$ & 19 & & & \\
\hline
\end{tabular}

variations in forces is the slight variation in mounting of dynamometer over fixture which in turn is mounted over the turret of CNC lathe machine (Fig. 1).

Based on the design of experiments and the response measured (Table 6), quadratic equation similar to Eq. 3 was developed by calculating regression coefficient for residual stresses and this is shown as Eq. 4:

$$
\begin{aligned}
R S= & -4362.24+4.184 \times V_{c}+9144.47 \times f+3019.17 \times a_{p}-1.46 e-3 \times V_{c}^{2}-30567.54 \times f^{2} \\
& -2102.54 \times a_{p}^{2}-2.31 \times V_{c} \times f-1.29 \times V_{c} \times a_{p}+7444.7 \times f \times a_{p}
\end{aligned}
$$

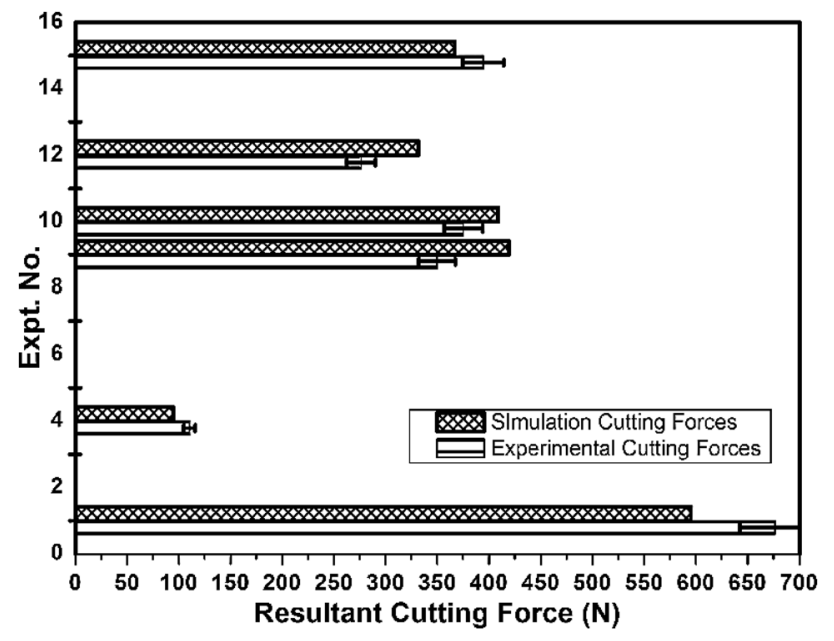

Fig. 7 Comparison between Experimental and simulation cutting forces where RS $=$ Residual Stress, $\mathrm{V}_{\mathrm{c}}=$ Cutting Speed $\mathrm{m} / \mathrm{min}$, $f=$ feed rate $\mathrm{mm} / \mathrm{rev}, \mathrm{a}_{\mathrm{p}}=$ depth of cut.

\subsection{Analysis of variance}

The analysis of variance (ANOVA) is used to check total variability in the response variable. It is done through dividing total sum of square into sum of square due to model and sum of square due to error. The test for significance of variables is done with $P$ value (probability). For statistics, $p$ value is less than 0.05 is the probability of the predicted model shows its significance in terms of statistics. Analysis of variance was performed to see the validity of model as shown in Table 8.

\subsection{Backward elimination procedure for developed model evaluation}

Insignificant terms in developed model found from ANOVA can be avoided using variable selection method. 
Table 9 ANOVA for modified model for residual stress

\begin{tabular}{llrlrl}
\hline Source & Sum of square & DF & Mean of Square & F value & P value Prob $>\mathrm{F}$ \\
\hline Model & $1.441 \mathrm{E}+006$ & 5 & $2.883 \mathrm{E}+005$ & 8.53 & 0.0007 \\
$\mathrm{~V}_{\mathrm{c}}$ & $4.940 \mathrm{E}+005$ & 1 & $4.940 \mathrm{E}+005$ & 14.62 & 0.0019 \\
$\mathrm{~F}$ & $2.643 \mathrm{E}+005$ & 1 & $2.643 \mathrm{E}+005$ & 7.82 & 0.0143 \\
$\mathrm{a}_{\mathrm{p}}$ & $2.737 \mathrm{E}+005$ & 1 & $2.737 \mathrm{E}+005$ & 8.10 & 0.0130 \\
$\mathrm{~V}_{\mathrm{c}} 2$ & $2.231 \mathrm{E}+005$ & 1 & $2.231 \mathrm{E}+005$ & 6.60 & 0.0223 \\
$\mathrm{a}_{\mathrm{p}} 2$ & $2.231 \mathrm{E}+005$ & 1 & $2.231 \mathrm{E}+005$ & 6.60 & 0.0223 \\
Residual & $4.731 \mathrm{E}+005$ & 14 & $33,796.14$ & & \\
Lack of fit & $4.731 \mathrm{E}+005$ & 9 & $52,571.77$ & & \\
Pure error & 0.000 & 5 & 0.000 & & \\
Core Total & $1.914 \mathrm{E}+006$ & 19 & & &
\end{tabular}

Fig. 8 Normal probability plot for residual stress

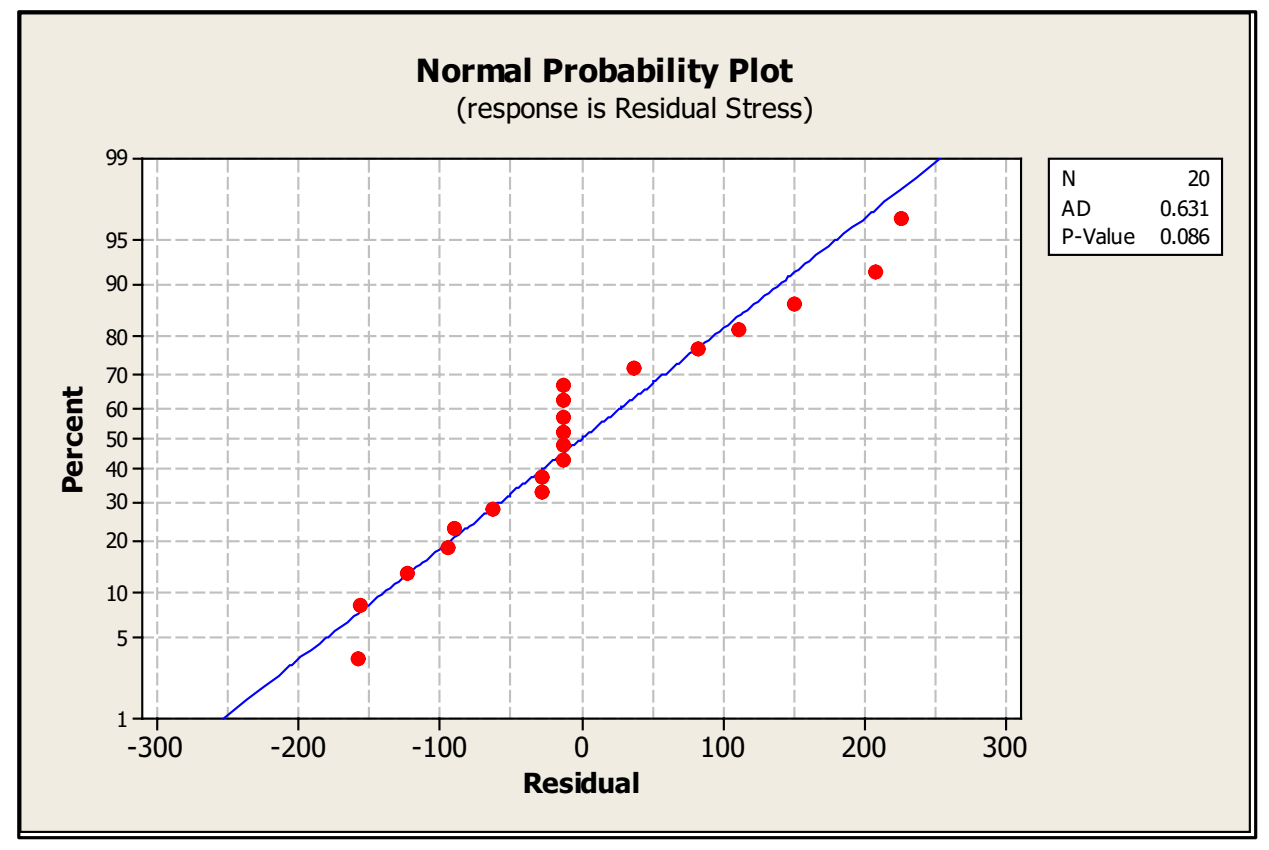

Reduced quadratic model is obtained using, the backward regression elimination method (also known as stepwise deletion) such that modified model clarifies the response. In the stepwise deletion method, F value is calculated as ratio between mean square error (due to regression) to the mean square error (due to residual) for significance of design variable is performed with sequence begin with full model. Insignificant variables with the highest $p$ value (e.g. $p>0.05$ ) and lowest $F$ value are removed from the full model. As discussed above, residual stress model developed after removing insignificant terms is given in Eq. 5
In Table 9, F value showed improvement as $8.53 \mathrm{com}$ pared to 7.93 from Table 6. Normal plot of residuals as shown in Fig. 8 lies on the straight lines and thus satisfies normality. Developed model is also verified with additional simulation performed at different cutting parameters than used in main simulations. Predicted residual stress from RSM model (at cutting speed $110 \mathrm{~m} /$ $\mathrm{min}$, feed rate $0.16 \mathrm{~mm} / \mathrm{rev}$ and depth of cut of $0.65 \mathrm{~mm}$ ) was found as $-365.96 \mathrm{MPa}$ compared to simulated value of $-366.38 \mathrm{MPa}$. Both simulated and predicted values are found almost identical and prove better prediction

$R S=-2807.32+2.667 \times V_{c}+2782.43 \times f+2405.46 \times a_{p}-1.37 e-3 \times V_{c}^{2}-1981.13 \times a_{p}^{2}$

For inspection the adequacy of reduced model, ANOVA is performed and results are shown in Table 9. ability of the model. From Eq. 5 it is clear that in turning operation, cutting parameters apart from affecting 

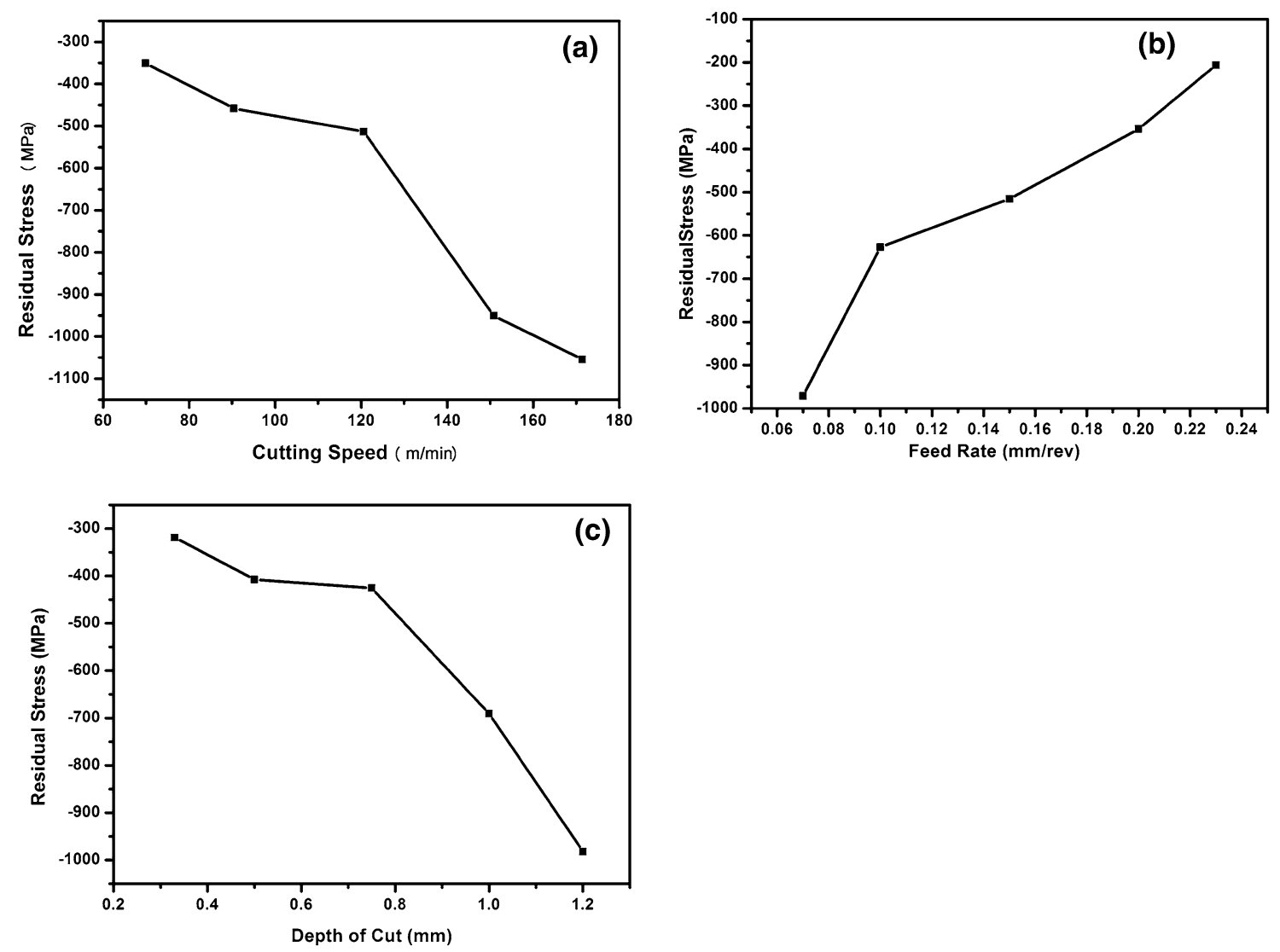

Fig. 9 Influence of cutting parameters on residual stresses $V_{s} \mathbf{a}$ feed rate, $\mathbf{b}$ cutting speed and $\mathbf{c}$ depth of cut

individually are likely to interrelate with each other and affect the residual stress. In other words, linear relationship does not explain residual stress in terms of cutting parameters. Instead, a polynomial model gives better prediction with higher correlation coefficient. Similar results are obtained in milling operation of titanium alloys by Sridhar et al. [34].

\subsection{Influence of cutting parameters on residual stress}

In this subsection, influence of cutting parameters on residual stress is presented. Simulations are performed and the results for each test are presented and then the tests are compared to each other in order to find a trend in the results and to draw conclusions on the effect of cutting parameters on induced residual stress. Main effect of individual cutting parameter was observed while keeping other cutting parameters at center level. Main effect plot of each cutting parameters are shown in Fig. 9a-c. The above variation of residual stress is due to collective outcome of thermal effect and mechanical loading over machined surfaces.

\subsubsection{Effect of cutting speed}

From Fig. 9a it is clear that with increase in cutting speed, surface residual stress becomes more compressive. Starting from $-350 \mathrm{MPa}$ at $70 \mathrm{~m} / \mathrm{min}$ (similar to results obtained by Sun et al. [24]) to $-1054 \mathrm{MPa}$ at high speed of $171.4 \mathrm{~m} /$ min. Possible reason for this trend is that at high cutting speed, formation of segmented chips along with faster chip flow in the cutting zone leads to large heat evacuation $[9,17]$. This leads to drop in temperature at machined surface coupled with an increase in compressive residual stresses [28]. With increase in cutting speed, tool flank wear increases rapidly in the machining of titanium alloys. This, in turn increases rubbing/contact of tool flank with the workpiece and ploughing effect dominates. Therefore, plastic deformation dominates the thermal effect and generates compressive residual stresses at surface.

\subsubsection{Effect of feed rate}

From Fig. $9 \mathrm{~b}$ it is clear that with increase in feed rate, surface residual stress becomes less compressive. At $0.07 \mathrm{~mm} /$ rev surface residual stress is found to be $-971.13 \mathrm{MPa}$ whereas at $0.23 \mathrm{~mm} / \mathrm{rev}$ it reduces to $-206.1 \mathrm{MPa}$. During 


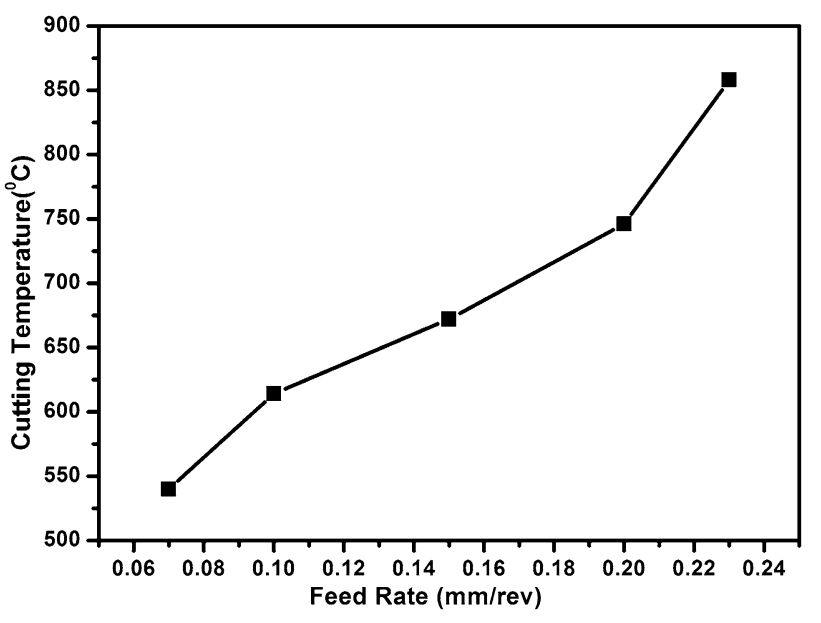

Fig. 10 Variation of cutting temperature with feed rate

the cutting process with high feed rate tensile strain increases in the machined surfaces [33]. At high feed rate contact time between tool and workpiece reduces due to which heat release through chip is reduced [32]. This results in high temperature in turning of titanium alloys. Figure 10 show cutting temperature generated in FEM simulation at feed rates used. It can be seen from the figure that cutting temperature increases up to $858^{\circ} \mathrm{C}$ at feed rate of $0.23 \mathrm{~mm} / \mathrm{rev}$ whereas it reduces to $540{ }^{\circ} \mathrm{C}$ at $0.07 \mathrm{~mm} / \mathrm{rev}$. Similar ranges of cutting temperatures are also reported by Özel et al. and Chen et al. [14, 20] in machining of titanium alloys. Also, due to increase in feed rate, material removal rate increases which in turns increase cutting energy resulting in overall temperature rise in the deformation zone [34]. Therefore, at high feed rate domination of thermal effect reduces compressive residual stresses at machined surface.

\subsubsection{Effect of depth of cut}

From Fig. $9 c$ it is clear that with increase in depth of cut surface residual stress becomes more compressive starting from $-318.98 \mathrm{MPa}$ at $0.33 \mathrm{~mm}$ depth of cut to $-982.1 \mathrm{MPa}$ at $1.17 \mathrm{~mm}$ depth of cut. Since titanium alloy is having strength, higher than other steel alloys, it requires higher cutting forces to remove small layer at surface. Forces generated in the FE simulation are confirmed through experimental results as shown in Fig. 7. At high depth of cut large material comes in contact with the tool and requires higher cutting forces in machining of titanium alloys. This leads to high friction and enfolding occurs between the cutting tool and the workpiece upon the covering layer, and cause severe plastic deformation. Therefore, due to domination of mechanical deformation more compressive stress is produced in the machined surface.

\subsubsection{Interaction plots of cutting parameters over residual stress}

Figure $11 a-c$ shows the interaction plot (3D surface) of cutting parameters over residual stress. 3D surface plots show the combined effects of cutting parameters over the residual stress. Figure $11 \mathrm{a}-\mathrm{c}$ confirms the highlights of main effect plot of cutting parameters over residual stress. From Fig. 11a, it is clear that for getting more compressive residual stress, higher cutting speed and lower feed rate should be consider. Similarly Fig. 11b, c shows similar trend to the main effect plot shown in Fig. 9b, c. It is clear from the Fig. $11 \mathrm{~b}, \mathrm{c}$, which for getting higher compressive residual stress combination of lower feed rate and higher depth of cut should be used.

\subsubsection{Effect of cutting force on residual stress}

As discussed in the experimentation, that cutting forces are also measured experimentally during turning of Ti-6Al-4V. Cutting forces measured using 3D FEM simulation and experimentation showed good agreement as shown in Fig. 7. This suggests that Johnson-Cook model used for numerical simulation with assumed constants is quite well. Figure 12 shows the variations of residual stress with cutting forces. It is clear from the Fig. 12 that as cutting forces increases, compressive residual stress also increases. Cutting forces increases due large plastic deformation during machining of Ti-6Al-4V. Increase in cutting forces represents the domination of mechanical loading due large plastic deformation thus increases the compressive hoop (circumferential) residual stresses. It is also found in the literatures that due to low thermal conductivity of titanium alloys, temperature increases in the cutting zone increase results in thermal softening [41-44]. Hence the material deforms elastically which results in lowering of cutting forces. Therefore it is observed that higher cutting forces during the machining represents the domination of mechanical loading over thermal loading which results in increase in compressive hoop (circumferential) residual stress.

\section{Optimization by desirability approach}

In this section optimum cutting parameters are found for maximizing surface compressive residual stress. Response based desirability approach was used for maximizing surface compressive stress. In desirability based procedure, higher desirability solution is preferred among different best solutions. Table 10 shows ranges of variables and their corresponding weights used for optimization. For multi response optimization, all the response values are transformed into dimensionless desirability value (d). Value of 
(a)

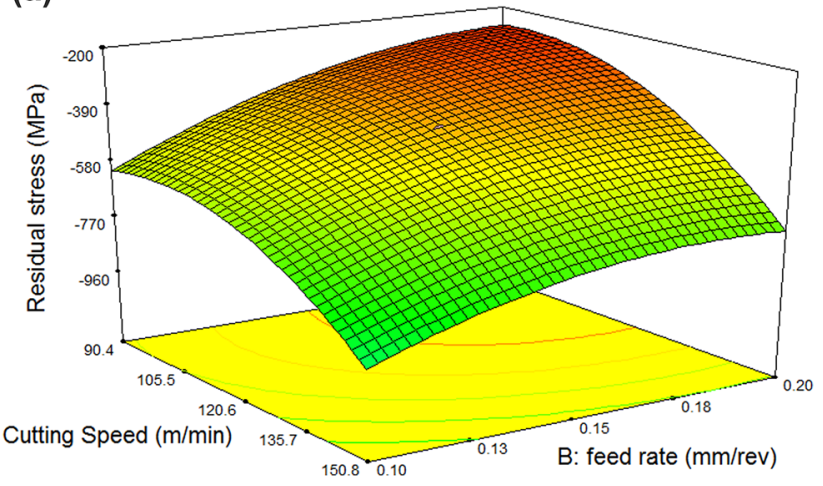

(b)

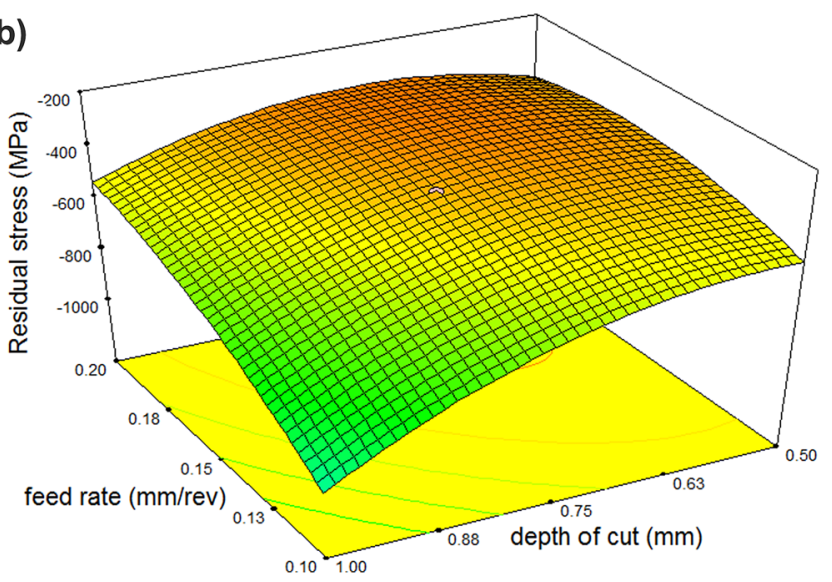

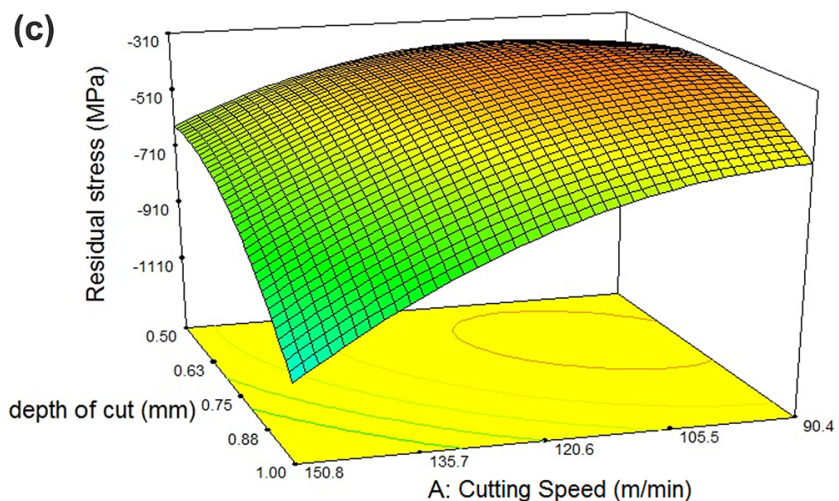

Fig. 11 Interaction plots Residual stress Vs a cutting speed and feed rate, $\mathbf{b}$ feed rate and depth of cut and $\mathbf{c}$ depth of cut and cutting speed

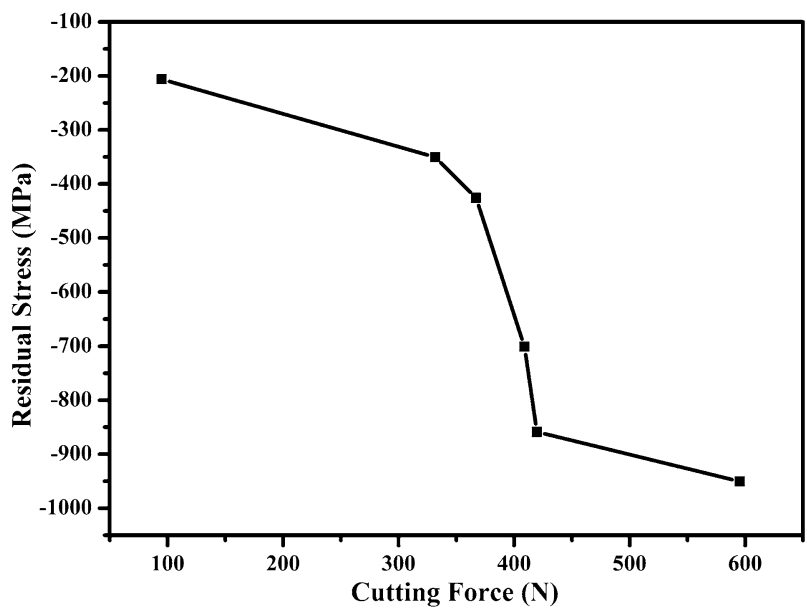

Fig. 12 Variation of residual stress with cutting forces d generally lies between 0 and $1(0 \leq d \leq 1)$, where $d=0$ means response is not valid and $\mathrm{d}=1$ means response is valid and desirable. In this case the goal for Residual stress is to minimise it. Since compressive stress has negative sign, in order to maximise surface compressive stress its magnitude should minimise. Therefore, for minimization;

$\mathrm{d}=1$ when minimum $\mathrm{RS}_{\text {sim }} \leq$ low value of $\mathrm{RS}_{\text {sim }}$;

$\mathrm{d}=0$ when minimum $\mathrm{RS} \geq$ high value of $\mathrm{RS}$ and

$\mathrm{d}=\left(\frac{\text { high } \mathrm{RS}_{\text {sim }}-\mathrm{RS}}{\text { high } \mathrm{RS}_{\text {sim }}-\text { low } R S_{\text {sim }}}\right)$ When low $\mathrm{RS}_{\text {sim }} \leq \mathrm{RS}_{\text {sim }} \leq$ high $\mathrm{RS}_{\text {sim }}$

where $\mathrm{RS}_{\text {sim }}=$ Simulated Residual Stress.

The optimum value of parameters are found as cutting speed $=171.4 \mathrm{~m} / \mathrm{min}$, feed rate $=0.07 \mathrm{~mm} / \mathrm{rev}$ and depth of cut $=0.8 \mathrm{~mm}$ and corresponding surface compressive residual stress is: $-1495.97(\mathrm{MPa})$. Confirmation simulation was performed based on optimum cutting speed, feed
Table 10 Optimization criteria for desirability approach

\begin{tabular}{lccllll}
\hline Parameter or response & Lower limit & Upper limit & Weight & Importance & Criteria & Desirability \\
\hline Cutting speed $(\mathrm{m} / \mathrm{min})$ & 69.9 & 171.4 & 1 & 3 & In range & 1 \\
Feed rate $(\mathrm{mm} / \mathrm{rev})$ & 0.07 & 0.23 & 1 & 3 & In range & 1 \\
Depth of cut $(\mathrm{mm})$ & 0.33 & 1.2 & 1 & 3 & In range & 1 \\
Residual stress $(\mathrm{MPa})$ & -1419.2 & -206.1 & 1 & 5 & Minimize & 1 \\
\hline
\end{tabular}


Table 11 Confirmation test results based on RSM optimization

\begin{tabular}{lccc}
\hline Parameters & Simulation & Optimum RSM & \% Error \\
\hline Cutting speed $(\mathrm{m} / \mathrm{min})$ & 171.4 & 171.4 & \\
Feed rate $(\mathrm{mm} / \mathrm{rev})$ & 0.07 & 0.07 & \\
Depth of cut $(\mathrm{mm})$ & 0.8 & 0.8 & \\
Residual stress $(\mathrm{MPa})$ & -1373.36 & -1495.97 & 8.196 \\
\hline
\end{tabular}

rate, depth of cut. The error between simulation results and RSM prediction is as shown in Table 11. Confirmation results conclude that the RSM model for predicting residual stress is accurate.

\section{Conclusions}

In this study, RSM based prediction model is developed for residual stress with utilisation of 3D FE simulations in turning of Ti-6Al-4V. Simulation results showed compressive residual stress at the machined surface for machining conditions. These results are validated with experimental results. It is concluded from the results that RSM based model can predict residual stress with reasonable accuracy. As compressive residual stresses are desirable to improve the fatigue life of components, using higher value of cutting speed and depth of cut is desirable for inducing higher compressive residual stress in Ti-6Al-4V. Optimization based on response surface desirability approach are validated with confirmation test suggest optimum cutting parameters for desirable compressive residual stresses. This predictive model can help manufacturing industry such as aerospace, biomedical and automobile which require high standards and functional reliability for their manufactured products.

Funding This work is funded through TEQIP II, Visvesvaraya National Institute of Technology, by MHRD, Govt. of INDIA.

\section{Compliance with ethical standards}

Conflict of interest The authors declare that they have no conflict of interest.

\section{References}

1. Ezugwu EO, Wang ZM (1997) Titanium alloys and their machinability-a review. J Mater Process Technol 68(3):262-274. https:// doi.org/10.1016/S0924-0136(96)00030-1
2. Sharma A, Sharma MD, Sehgal R (2013) Experimental study of machining characteristics of titanium alloy (Ti-6Al-4V). Arab J Sci Eng 38(11):3201-3209. https://doi.org/10.1007/s1336 9-012-0451-7

3. Ulutan D, Ozel T (2011) Machining induced surface integrity in titanium and nickel alloys: a review. Int J Mach Tools Manuf 51(3):250-280. https://doi.org/10.1016/j.ijmachtool s.2010.11.003

4. Outeiro JC, Pina JC, M'Saoubi R, Pusavec F, Jawahir IS (2008) Analysis of residual stresses induced by dry turning of difficultto-machine materials. CIRP Ann Manuf Technol 57(1):77-80. https://doi.org/10.1016/j.cirp.2008.03.076

5. Kenda J, Pusavec F, Kopac J (2011) Analysis of residual stresses in sustainable cryogenic machining of nickel based alloyInconel 718. J Manuf Sci Eng 133(4):041009-041009. https:// doi.org/10.1115/1.4004610

6. Özel T, Ulutan D (2012) Prediction of machining induced residual stresses in turning of titanium and nickel based alloys with experiments and finite element simulations. CIRP Ann Manuf Technol 61(1):547-550. https://doi.org/10.1016/j. cirp.2012.03.100

7. M'Saoubi R, Outeiro JC, Chandrasekaran H, Dillon OW Jr, Jawahir IS (2008) A review of surface integrity in machining and its impact on functional performance and life of machined products. Int J Sustain Manuf 1(1-2):203-236. https://doi. org/10.1504/IJSM.2008.019234

8. Che-Haron $\mathrm{CH}$, Jawaid A (2005) The effect of machining on surface integrity of titanium alloy $\mathrm{Ti}-6 \% \mathrm{Al}-4 \% \mathrm{~V}$. J Mater Process Technol 166(2):188-192. https://doi.org/10.1016/j.jmatprotec .2004.08.012

9. M'Saoubi R, Outeiro JC, Changeux B, Lebrun JL, Morão Dias A (1999) Residual stress analysis in orthogonal machining of standard and resulfurized AISI $316 \mathrm{~L}$ steels. J Mater Process Technol 96(1-3):225-233. https://doi.org/10.1016/S0924 -0136(99)00359-3

10. Brinksmeier E, Cammett JT, König W, Leskovar P, Peters J, Tönshoff HK (1982) Residual stresses-measurement and causes in machining processes. CIRP Ann Manuf Technol 31(2):491-510. https://doi.org/10.1016/S0007-8506(07)60172-3

11. Arunachalam RM, Mannan MA, Spowage AC (2004) Residual stress and surface roughness when facing age hardened Inconel 718 with CBN and ceramic cutting tools. Int J Mach Tools Manuf 44(9):879-887. https://doi.org/10.1016/j.ijmac htools.2004.02.016

12. Mohammadpour M, Razfar MR, Jalili Saffar R (2010) Numerical investigating the effect of machining parameters on residual stresses in orthogonal cutting. Simul Model Pract Theory 18(3):378-389. https://doi.org/10.1016/j.simpat.2009.12.004

13. Dahlman $P$, Gunnberg F, Jacobson M (2004) The influence of rake angle, cutting feed and cutting depth on residual stresses in hard turning. J Mater Process Technol 147(2):181-184. https ://doi.org/10.1016/j.jmatprotec.2003.12.014

14. Özel T, Zeren E (2005) Finite element modeling of stresses induced by high speed machining with round edge cutting tools. In: ASME 2005 international mechanical engineering congress and exposition, Orlando, Florida, 2005. American Society of Mechanical Engineers, pp 1279-1287

15. Krishnakumar P, Sripathi J, Vijay P, Ramachandran KI (2016) Finite element modelling and residual stress prediction in end milling of Ti6Al4 valloy. IOP Conf Ser Mater Sci Eng 149:012154. https://doi.org/10.1088/1757-899x/149/1/012154

16. Gonzalez-Perez I, Fuentes-Aznar A (2017) Implementation of a finite element model for stress analysis of gear drives based on multi-point constraints. Mech Mach Theory 117:35-47. https://doi.org/10.1016/J.MECHMACHTHEORY.2017.07.005 
17. Schlegl H, Dawson R (2017) Finite element analysis and modelling of thermal stress in solid oxide fuel cells. Proc Inst Mech Eng A J Power Energy 231:654-665. https://doi. org/10.1177/0957650917716269

18. Prasad CS (2009) Finite element modeling to verify residual stress in orthogonal machining

19. Salio M, Berruti T, De Poli G (2006) Prediction of residual stress distribution after turning in turbine disks. Int J Mech Sci 48(9):976-984. https://doi.org/10.1016/j.ijmecsci.2006.03.009

20. Pan Zhipeng, Shih Donald S, Garmestani Hamid, Liang Steven Y (2017) Residual stress prediction for turning of Ti-6AI-4V considering the microstructure evolution. Proc IMechE B J Eng Manuf 1:9. https://doi.org/10.1177/0954405417712551

21. Chen L, El-Wardany TI, Harris WC (2004) Modelling the effects of flank wear land and chip formation on residual stresses. CIRP Ann Manuf Technol 53(1):95-98. https://doi.org/10.1016/ S0007-8506(07)60653-2

22. Umbrello D, M'Saoubi R, Outeiro JC (2007) The influence of Johnson-Cook material constants on finite element simulation of machining of AISI 316L steel. Int J Mach Tools Manuf 47(3-4):462-470. https://doi.org/10.1016/j.ijmachtool s.2006.06.006

23. Fitzpatrick M, Fry A, Holdway P, Kandil F, Shackleton J, Suominen $L$ (2005) Determination of residual stresses by $X$-ray diffraction. In: National Physical Laboratory. Teddington, Middlesex, United Kingdom

24. Sun J, Guo YB (2009) A comprehensive experimental study on surface integrity by end milling Ti-6Al-4V. J Mater Process Technol 209(8):4036-4042. https://doi.org/10.1016/j.jmatp rotec.2008.09.022

25. Jianxin D, Yousheng L, Wenlong S (2008) Diffusion wear in dry cutting of Ti-6Al-4V with WC/Co carbide tools. Wear 265(1112):1776-1783. https://doi.org/10.1016/j.wear.2008.04.024

26. Capello E (2005) Residual stresses in turning: part I: influence of process parameters. J Mater Process Technol 160(2):221228. https://doi.org/10.1016/j.jmatprotec.2004.06.012

27. Miguélez $M H$, Zaera R, Molinari A, Cheriguene R, Rusinek A (2009) Residual stresses in orthogonal cutting of metals: the effect of thermomechanical coupling parameters and of friction. J Therm Stresses 32(3):269-289. https://doi. org/10.1080/01495730802637134

28. Abboud E, Shi B, Attia H, Thomson V, Mebrahtu Y (2013) Finite element-based modeling of machining-induced residual stresses in Ti-6Al-4V under finish turning conditions. Procedia CIRP 8:63-68. https://doi.org/10.1016/j.procir.2013.06.066

29. Myers RH, Montgomery DC, Anderson-Cook CM (2009) Response surface methodology: process and product optimization using designed experiments, 3rd edn. Wiley, Hoboken

30. El-Tayeb NSM, Yap TC, Venkatesh VC, Brevern PV (2009) Modeling of cryogenic frictional behaviour of titanium alloys using response surface methodology approach. Mater Des 30(10):4023-4034. https://doi.org/10.1016/j.matdes.2009.05.020

31. Choudhary AK, Chelladurai H, Kannan C (2015) Optimization of combustion performance of bioethanol (water hyacinth) diesel blends on diesel engine using response surface methodology. Arab J Sci Eng 40(12):3675-3695. https://doi. org/10.1007/s13369-015-1810-y

32. Nemat-Nasser S, Guo W-G, Nesterenko VF, Indrakanti SS, Gu Y-B (2001) Dynamic response of conventional and hot isostatically pressed Ti-6Al-4V alloys: experiments and modeling. Mech Mater 33(8):425-439. https://doi.org/10.1016/ S0167-6636(01)00063-1

33. Lee W-S, Lin C-F (1998) Plastic deformation and fracture behaviour of $\mathrm{Ti}-6 \mathrm{Al}-4 \mathrm{~V}$ alloy loaded with high strain rate under various temperatures. Mater Sci Eng A 241(1):48-59. https://doi.org/10.1016/S0921-5093(97)00471-1

34. Sridhar BR, Devananda G, Ramachandra K, Bhat R (2003) Effect of machining parameters and heat treatment on the residual stress distribution in titanium alloy IMI-834. J Mater Process Technol 139(1-3):628-634. https://doi.org/10.1016/S0924 -0136(03)00612-5

35. Mantle AL, Aspinwall DK (2001) Surface integrity of a high speed milled gamma titanium aluminide. J Mater Process Technol 118(1-3):143-150. https://doi.org/10.1016/S0924 -0136(01)00914-1

36. Özel T, Zeren E (2005) Finite element modeling of stresses induced by high speed machining with round edge cutting tools. In: ASME 2005 international mechanical engineering congress and exposition 2005. American Society of Mechanical Engineers, pp 1279-1287

37. Xin H, Shi Y, Ning L, Zhao T (2016) Residual stress and affected layer in disc milling of titanium alloy. Mater Manuf Processes 31(13):1645-1653. https://doi.org/10.1080/10426 914.2015.1090583

38. Capello E, Davoli P, Bassanini G, Bisi A (1999) Residual stresses and surface roughness in turning. J Eng Mater Technol 121(3):346-351. https://doi.org/10.1115/1.2812385

39. Hua J, Shivpuri R, Cheng X, Bedekar V, Matsumoto Y, Hashimoto F, Watkins TR (2005) Effect of feed rate, workpiece hardness and cutting edge on subsurface residual stress in the hard turning of bearing steel using chamfer + hone cutting edge geometry. Mater Sci Eng A 394(1-2):238-248. https:// doi.org/10.1016/j.msea.2004.11.011

40. Çelik YH, Kilickap E, Güney M (2016) Investigation of cutting parameters affecting on tool wear and surface roughness in dry turning of Ti-6Al-4V using CVD and PVD coated tools. J Braz Soc Mech Sci Eng 39(6):1-9. https://doi.org/10.1007/ s40430-016-0607-6

41. Zhang S, Li JF, Sun J, Jiang F (2010) Tool wear and cutting forces variation in high-speed end-milling Ti-6Al-4V alloy. Int J Adv Manuf Technol 46(1):69-78. https://doi.org/10.1007/ s00170-009-2077-9

42. Dandekar CR, Shin YC, Barnes J (2010) Machinability improvement of titanium alloy (Ti-6Al-4V) via LAM and hybrid machining. Int J Mach Tools Manuf 50(2):174-182. https:// doi.org/10.1016/j.ijmachtools.2009.10.013

43. Abele E, Fröhlich B (2008) High speed milling of titanium alloys. Adv Prod Eng Manag 3(3):131-140

44. Meyer HW, Kleponis DS (2001) Modeling the high strain rate behavior of titanium undergoing ballistic impact and penetration. Int J Impact Eng 26(1):509-521. https://doi.org/10.1016/ S0734-743X(01)00107-5

Publisher's Note Springer Nature remains neutral with regard to jurisdictional claims in published maps and institutional affiliations. 